\title{
Determination of Serum Lipid Peroxide Levels in Healthy and Diseased Subjects by Use of a Methylene Blue Derivative
}

\author{
Tohru Tateishi, ${ }^{*}$ Noboru Yoshimine, and Fumio Kuzuya \\ Department of Geriatrics, Nagoya University School of Medicine, \\ Tsuruma-cho, Showa-ku, Nagoya 466, Japan
}

(Received November 24, 1988)

\begin{abstract}
Summary By using a newly developed assay method for lipid peroxides based on their reaction with a leucomethylene blue derivative, we investigated serum lipid peroxides (LPO) in healthy and in diseased subjects. In 116 healthy subjects, the mean LPO level obtained was $1.45 \pm$ $1.37 \mathrm{nmol} / \mathrm{ml}$ and showed significant correlations with total bilirubin, direct bilirubin, phospholipid, total cholesterol, high density lipoprotein-cholesterol, and low density lipoprotein-cholesterol. In 12 hypertensive patients, the LPO value was significantly higher $(2.60 \pm 2.08$ $\mathrm{nmol} / \mathrm{ml}$ ) compared with the healthy control, and LPO showed a significant correlation with serum globulin. In 16 hyperlipidemic subjects, the value was $1.50 \pm 0.86 \mathrm{nmol} / \mathrm{ml}$ and correlated with fibrinogen, white blood cells, and nonesterified fatty acids. In 19 diabetics, the level was not significantly different with that in the healthy control, and correlated with fasting blood sugar, total protein, and urea nitrogen. In 10 patients with liver dysfunction, LPO was $1.60 \pm 1.33 \mathrm{nmol} / \mathrm{ml}$ and correlated with white blood cells, chloride, and nonesterified fatty acids.
\end{abstract}

Key Words: lipid peroxides, methylene blue derivative, clinical parameters

Lipid peroxidation is a complex process whereby unsaturated lipids react with molecular oxygen to yield lipid peroxides (LPO) in a radical chain reaction [1]. It has been claimed that LPO is associated with the aging process [2], atherosclerosis [3], and other disease processes $[4,5]$. Among many methods for LPO determination, the thiobarbituric acid (TBA) method has been the most commonly used in clinical fields. This method is based on the acid breakdown of LPO into malondialdehyde (MDA) molecules, which subsequently react with TBA to

*To whom correspondence should be addressed. 
produce substances suitable for assay by colorimetry [6] or fluorophotometry [7]. This method has the advantages of sensitivity and simplicity, but has also been claimed to measure MDA-like substances. Furthermore, although TBA reacts with lipid peroxides, the relation is not equimolar $[6,8]$. This is the reason why other methods for determination of LPO have been investigated.

A newly developed assay method for LPO, the Hb-MB method, is based on the reaction of LPO with a derivative of methylene blue and specifically detects lipid hydroperoxides on an equimolar basis [9]. Neither hydrogen peroxide nor aldehydes such as MDA react in this method. And this method has been proved to be useful for detection of LPO in foods [10], and there was a report to adopt this method to the automated procedure [11]. We also found earlier that this method can also be used with high-performance liquid chromatography [12]. Further by using this method, we reported [13] that serum LPO levels of the healthy subjects correlated positively with height, body weight, and hemoglobin, but not with age, and that rat serum LPO levels measured by this method and by the TBA method did not show a significant correlation. Afterwards it was recognized $[14,15]$ that the kit utilizing this new method also measured iron-transferrin complex (holo-transferrin) besides LPO. However, the addition of a chelating agent to the original kit solved this problem [14].

In the present study, we determined the serum LPO value in healthy and diseased subjects by use of this improved procedure, and investigated the correlation between the LPO level and other clinical parameters.

\section{MATERIALS AND METHODS}

Subjects. For LPO determination, fasting blood samples were obtained from 158 male employees of an automobile company, who were selected at random from about 6,000 employees. LPO was measured immediately after sampling. The following clinical parameters were also investigated and statistical analysis was done, using the SAS (Statistical Analysis System); age, height, weight, obesity (Obes), right and left grip strength (Grip [Rt], Grip [Lt]), vital capacity (VC), forced expiratory volume in the first second $\left(\mathrm{FEV}_{1.0}\right)$, systolic and diastolic blood pressure (SBP, DBP), erythrocyte sedimentation rate (ESR), red blood cells (RBC), hemoglobin $(\mathrm{Hb})$, hematocrit $(\mathrm{Ht})$, white blood cells (WBC), total protein (TP), albumin (Alb), globulin (Glob), albumin-globulin ratio $(A / G)$, urea nitrogen $(\mathrm{BUN})$, creatinine $(\mathrm{Cr})$, uric acid $(\mathrm{UA})$, sodium $(\mathrm{Na})$, potassium $(\mathrm{K})$, chloride $(\mathrm{Cl})$, calcium $(\mathrm{Ca})$, aspartate- and alanine-transaminase (GOT, GPT), alkaline phosphatase (ALP), gamma-glutamyl-transpeptidase (GGTP), total and direct bilirubin (TB, DB), fibrinogen (Fib), anti-thrombin-III (AT-III), fasting glucose (FBG), amylase (Amyl), triglyceride (TG), phospholipid (PL), nonesterified fatty acids (NEFA), total-, high density lipoprotein-, and low density lipoproteincholesterol (Tch, HDLch, and LDLch), and atherogenic index (AI).

Classification of subjects. The subjects were normal working employees, but 
they were divided into healthy and diseased groups from the results of clinical study and history taking. The criteria for "diseased" in the clinical study were as follows: Hyperlipidemia, total cholesterol greater than $250 \mathrm{mg} / \mathrm{dl}$ and/or triglyceride greater than $200 \mathrm{mg} / \mathrm{dl}$. Diabetes mellitus, fasting glucose greater than $110 \mathrm{mg} /$ dl. Hypertension, systolic blood pressure greater than $160 \mathrm{mmHg}$ and/or diastolic blood pressure greater than $95 \mathrm{mmHg}$. Liver dysfunction, aspartate-transaminase greater than $50 \mathrm{IU} /$ liter and/or gamma-glutamyl-transpeptidase greater than 100 $\mathrm{U} /$ liter.

Assay of serum lipid peroxides. The assay kit based on the Hb-MB method, Determiner LPO, was purchased from Kyowa Medex Co., Tokyo. We calculated the LPO content from the colorimetric change at $675 \mathrm{~nm}$, using a spectrophotometer UV-160 (Shimadzu Co., Kyoto). Serum LPO level was also measured by TBA fluorophotometry [7].

\section{RESULTS}

\section{Classification of subjects}

The numbers of subjects, classified by the above criteria, were as follows:116 healthy subjects, 16 subjects with hyperlipidemia, 19 with diabetes mellitus, 12 with hypertension, and 10 with liver dysfunction.

\section{LPO determination}

In healthy subjects, the mean $\pm \mathrm{SD}$ of serum LPO measured by the $\mathrm{Hb}-\mathrm{MB}$ method was $1.45 \pm 1.37 \mathrm{nmol} / \mathrm{ml}$. The range was from 0.00 to $7.91 \mathrm{nmol} / \mathrm{ml}$ (Fig. 1).

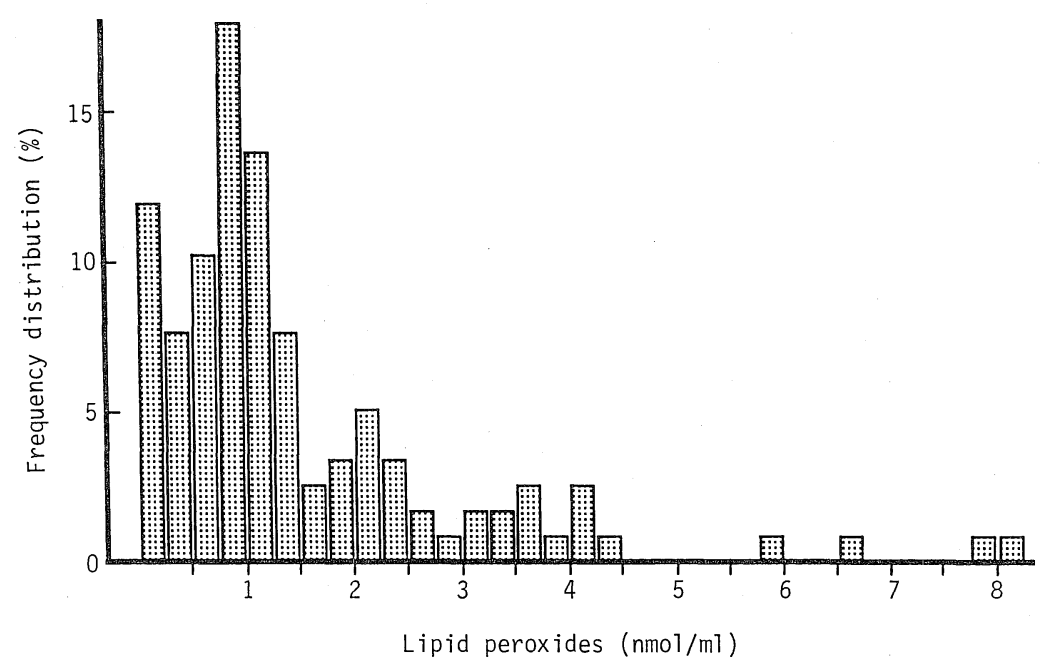

Fig. 1. Frequency distribution of serum lipid peroxides in healthy subjects. Number of subjects, 116. The mean \pm SD of LPO, $1.45 \pm 1.37 \mathrm{nmol} / \mathrm{ml}$. 


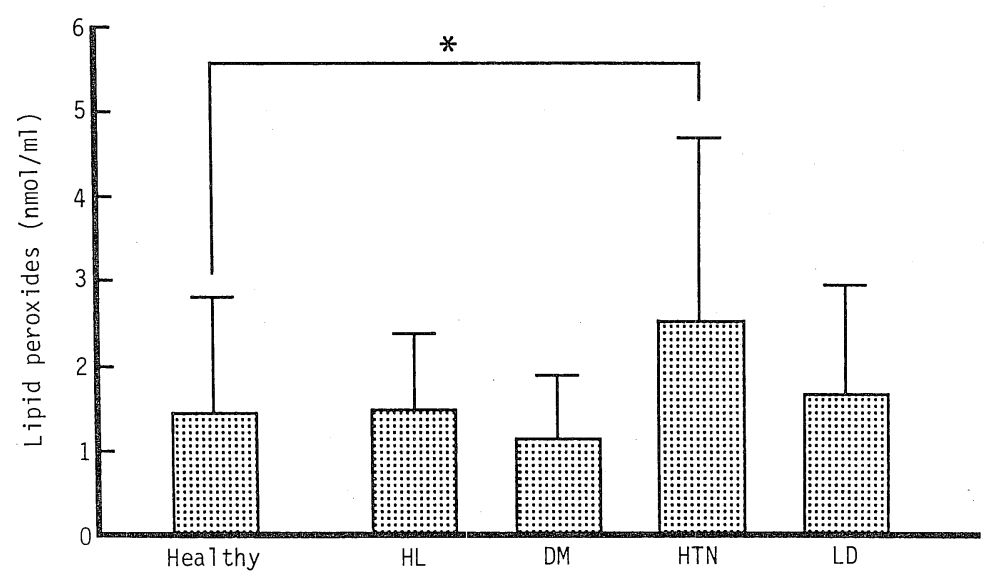

Fig. 2. Comparison of serum lipid peroxide levels between healthy subjects and patients. Healthy $(n=116)$; HL, hyperlipidemia $(n=16)$; DM, diabetes mellitus $(n=19)$; HTN, hypertension $(n=12)$; LD, liver dysfunction $(n=10) .{ }^{*} p<0.02$.

The tenth percentile value $\left(\mathrm{P}_{10}\right)$ was $0.21 \mathrm{nmol} / \mathrm{ml}$ and the ninetieth percentile value $\left(\mathrm{P}_{90}\right)$ was $3.54 \mathrm{nmol} / \mathrm{ml}$. The LPO obtained by the TBA method was $4.01 \pm$ $1.65 \mathrm{nmol} / \mathrm{ml}$.

The comparison of LPO levels measured by the Hb-MB method between healthy and diseased subjects is shown in Fig. 2. In hyperlipidemic patients, diabetic patients, hypertensive patients, and patients with liver function abnormality, the LPO levels were $1.50 \pm 0.86 \mathrm{nmol} / \mathrm{ml}\left(\mathrm{P}_{10}=0.55 \mathrm{nmol} / \mathrm{ml} ; \mathrm{P}_{90}=3.15 \mathrm{nmol} /\right.$ $\mathrm{ml}), 1.23 \pm 0.63\left(\mathrm{P}_{10}=0.59 ; \mathrm{P}_{90}=2.08\right), 2.60 \pm 2.08\left(\mathrm{P}_{10}=0.74 ; \mathrm{P}_{90}=6.92\right)$, and $1.60 \pm 1.33\left(\mathrm{P}_{10}=0.02 ; \mathrm{P}_{90}=3.86\right)$, respectively. In the case of hypertensive patients, the value was significantly higher than that in healthy subjects $(p<0.05)$.

\section{Clinical data and statistical analysis}

The result of single correlation study between LPO obtained by the Hb-MB method and clinical parameters in healthy subjects is shown in Table 1. Total bilirubin, direct bilirubin, phospholipid, total cholesterol, HDL-cholesterol, and LDL-cholesterol each showed a significant negative correlation with $\operatorname{LPO}(p<$ $0.05)$. No other parameters examined showed a significant correlation with LPO measured by the Hb-MB method.

The LPO level in hyperlipidemic patients showed a significant correlation with obesity $(r=-0.556)$, white blood cells $(r=0.745)$, fibrinogen $(r=0.522)$ and nonesterified fatty acids $(r=0.553)$. In diabetic patients, the LPO level correlated with fasting blood glucose $(r=0.519)$, total protein $(r=-0.458)$, urea nitrogen $(r=0.581)$ and left grip strength $(r=0.675)$. In hypertensive patients, LPO showed a significant correlation with serum globulin $(r=-0.594)$, and in patients with liver dysfunction, LPO correlated with white blood cells $(r=0.735)$, chloride $(r=-0.667)$, and nonesterified fatty acids $(r=0.770)$. 
Table 1. Single correlation coefficients between serum lipid peroxides measured by the $\mathrm{Hb}-\mathrm{MB}$ method and clinical parameters in 116 healthy subjects.

\begin{tabular}{lrlrlr}
\hline Age & 0.035 & TP & -0.149 & TB & $-0.192^{*}$ \\
Height & -0.075 & Alb & -0.097 & DB & $-0.214^{*}$ \\
Weight & 0.097 & Glob & -0.059 & Fib & 0.005 \\
Obes & 0.196 & A/G & 0.005 & AT-III & -0.095 \\
Grip (Rt) & -0.158 & BUN & 0.005 & FBG & -0.074 \\
$\quad(L t)$ & 0.002 & Cr & -0.000 & Amyl & -0.047 \\
VC & -0.100 & UA & -0.012 & TG & 0.027 \\
FEV & -0.037 & Na & -0.161 & PL & $-0.280^{*}$ \\
SBP & 0.026 & K & -0.042 & NEFA & -0.114 \\
DBP & 0.054 & Cl & 0.034 & Tch & $-0.333^{*}$ \\
ESR & -0.051 & Ca & 0.037 & HDLch & $-0.189^{*}$ \\
RBC & -0.077 & GOT & 0.093 & LDLch & $-0.251^{*}$ \\
Hb & 0.021 & GPT & 0.168 & AI & -0.039 \\
Ht & -0.035 & ALP & -0.108 & TBA & -0.120 \\
WBC & 0.110 & GGTP & -0.033 & & \\
\hline
\end{tabular}

${ }^{*} p<0.005$. For abbreviations, see text.

\section{DISCUSSION}

In this study, we would like to emphasize two points that the LPO value obtained by the $\mathrm{Hb}-\mathrm{MB}$ method $(1.45 \pm 1.37 \mathrm{nmol} / \mathrm{ml})$ was less than that found by the TBA method $(4.01 \pm 1.65 \mathrm{nmol} / \mathrm{ml})$ in the healthy subjects, and that the LPO level obtained by the former method did not show any significant change with age. However, by using the TBA method, we previously reported that plasma LPO increased with age [16], which was supported by other reports [4, 17]. These discrepancy between the two methods are probably due to the difference in the substances measured. This difference in estimated substances may explain the lack of correlation between the values obtained by the two methods.

Concerning the correlation between LPO value and clinical parameters, Hata et al. reported that the level measured by the TBA method correlates with urea nitrogen and serum calcium in healthy subjects [18]. In our study, total bilirubin, direct bilirubin, phospholipid, total cholesterol, HDL-cholesterol, and LDLcholesterol showed negative correlations with LPO measured by the improved $\mathrm{Hb}-\mathrm{MB}$ method. Because this improved $\mathrm{Hb}-\mathrm{MB}$ method is still quite new, further investigation is needed.

There have so far been no reports investigating the relation between LPO measured by this improved $\mathrm{Hb}-\mathrm{MB}$ method and aging or disease processes. This study revealed that the level of LPO was higher in patients with hypertension and that the levels of LPO were not statistically different in patients with hyperlipidemia, diabetes mellitus, or liver function abnormality. In this study, we did not observe high levels of LPO in diabetics or in patients suffering from liver diseases, in which high levels were reported based on the TBA method $[4,5]$.

Vol. 7, No. 2, 1989 
However, the fact that LPO measured by the Hb-MB method correlated positively with blood glucose might explain the atherosclerotic process in diabetic patients. Positive correlations of LPO with white blood cells and nonesterified fatty acids in subjects with liver dysfunction are other interesting points. These phenomena might reflect disease processes, but the reasons have not yet been revealed. Further studies utilizing this new method should uncover the relationships between LPO and the aging process and various disease processes.

\section{REFERENCES}

1. Pryor, W. A. (1976): The role of free radical reactions in biological systems, in Free Radicals in Biology, ed. by Pryor, W. A., Academic Press, New York, Vol. 1, pp. 1-49.

2. Harman, D. (1982): The free-radical theory of aging, in Free Radicals in Biology, ed. by Pryor, W. A., Academic Press, New York, Vol. 5, pp. 255-275.

3. Iwakami, M. (1965): Peroxides as a factor of atherosclerosis. Nagoya J. Med. Sci., 28, 5066.

4. Suematsu, T., Kaneda, T., Abe, H., Kikuchi, S., and Yagi, K. (1977): Serum lipoperoxide level in patients suffering from liver diseases. Clin. Chim. Acta, 79, 267-270.

5. Sato, Y., Hotta, N., Sakamoto, N., Matsuoka, S., Ohishi, N., and Yagi, K. (1979): Lipid peroxide level in plasma of diabetic patients. Biochem. Med., 21, 104-107.

6. Asakawa, T., and Matsushita, S. (1980): Thiobarbituric acid test for detecting lipid peroxides. Lipids, 14, 401-406.

7. Yagi, K. (1976): A simple fluorometric assay for lipoperoxide in blood plasma. Biochem. Med., 15, 212-216.

8. Ohkawa, H., Ohishi, N., and Yagi, K. (1978): Reaction of linoleic acid hydroperoxide with thiobarbituric acid. J. Lipid Res., 19, 1053-1057.

9. Ohishi, N., Ohkawa, H., Miike, A., Tatano, T., and Yagi, K. (1985): A new assay method for lipid peroxides using a methylene blue derivative. Biochem. Int., 10, 205-211.

10. Yagi, K., Kiuchi, K., Saito, Y., Miike, A., Kayahara, N., Tatano, T., and Ohishi, N. (1986): Use of a new methylene blue derivative for determination of lipid hydroperoxide in foods. Biochem. Int., 12, 367-371.

11. Tanaka, Y., Nishikawa, Y., Utagawa, A., Horikawa, M., Tomotake, A., Suganuma, H., Kanda, T., and Suematsu, T. (1986): Lipid peroxide measurement by the enzyme method and its clinical significance. Rinshobyori, 34, 120.

12. Tateishi, T., Yoshimine, N., and Kuzuya, F. (1988): Serum lipid peroxide levels and their distributions in the lipoprotein fractions by a new method. J. Jpn. Atheroscler. Soc., 15, 1585-1586.

13. Tateishi, T., Yoshimine, N., and Kuzuya, F. (1987): Serum lipid peroxide assayed by a new colorimetric method. Exp. Gerontol., 22, 103-111.

14. Yagi, K., Yamauchi, T., Kobayashi, S., Komura, S., Ohishi, N., Kayahara, N., and Tatano, T. (1987): Examination of lipid peroxide assay by the hemoglobin-methylene blue method. Lipid Peroxide Res., $11,38$.

15. Yoshida, K., Kaku, H., Nakajima, S., Okazaki, K., and Inaba, G. (1987): Correlation between serum lipid peroxide and serum iron in rheumatoid arthritis determined by a new Yagi colorimetric method. Igakunoayumi, 140, 171-172.

16. Yoshimine, N., Sato, Y., and Kuzuya, F. (1977): Lipid peroxide and aging, with special reference to vascular damage. Jpn. J. Geriatr., 15, 201-204.

17. Poubelle, P., Chaintreuil, J., Bensadoun, F., Blotman, F., Simon, L., and De Paulet, A.C. (1982): Plasma lipoperoxides and aging. Biomedicine, 36, 164-166.

18. Hata, Y., Aihara, K., and Miyazaki, K. (1978): A study of the relation between atherosclerosis and lipid peroxide. Jpn. J. Geriatr., 15, 192-200. 